\title{
Niobium near-surface composition during nitrogen infusion relevant for superconducting radio-frequency cavities
}

\author{
G. D. L. Semione ${ }^{1,2,{ }^{*}}$ A. Dangwal Pandey, ${ }^{1}$ S. Tober,${ }^{1,2}$ J. Pfrommer, ${ }^{1}$ A. Poulain, ${ }^{3}$ J. Drnec, ${ }^{3}$ \\ G. Schütz, ${ }^{4}$ T. F. Keller, ${ }^{1,2}$ H. Noei, ${ }^{1}$ V. Vonk, ${ }^{1}$ B. Foster, ${ }^{1,2,5}$ and A. Stierle ${ }^{1,2}$ \\ ${ }^{1}$ Deutsches Elektronen-Synchrotron DESY, D-22607 Hamburg, Germany \\ ${ }^{2}$ Fachbereich Physik, Universität Hamburg, D-20355 Hamburg, Germany \\ ${ }^{3}$ European Synchrotron Radiation Facility, 71 avenue des Martyrs, CS 40220, Grenoble Cedex 9, France \\ ${ }^{4}$ Max Planck Institute for Intelligent Systems, Heisenbergstrasse 1, D-70569 Stuttgart, Germany \\ ${ }^{5}$ University of Oxford, Keble Road, OXI 3RH, Oxford, United Kingdom
}

(Received 1 July 2019; published 31 October 2019)

\begin{abstract}
A detailed study of the near-surface structure and composition of $\mathrm{Nb}$, the material of choice for superconducting radio-frequency accelerator (SRF) cavities, is of great importance in order to understand the effects of different treatments applied during cavity production. By means of surface-sensitive techniques such as grazing incidence diffuse $\mathrm{x}$-ray scattering, $\mathrm{x}$-ray reflectivity, and $\mathrm{x}$-ray photoelectron spectroscopy, single-crystalline $\mathrm{Nb}(100)$ samples were investigated in and ex situ during annealing in an ultrahigh vacuum as well as in nitrogen atmospheres with temperatures and pressures similar to the ones employed in real $\mathrm{Nb}$ cavity treatments. Annealing of $\mathrm{Nb}$ specimens up to $800^{\circ} \mathrm{C}$ in a vacuum promotes a partial reduction of the natural surface oxides $\left(\mathrm{Nb}_{2} \mathrm{O}_{5}, \mathrm{NbO}_{2}\right.$, and $\left.\mathrm{NbO}\right)$ into $\mathrm{NbO}$. Upon cooling to $120^{\circ} \mathrm{C}$, no evidence of nitrogen-rich layers was detected after nitrogen exposure times of up to $48 \mathrm{~h}$. An oxygen enrichment below the $\mathrm{Nb}$-oxide interface and posterior diffusion of oxygen species towards the $\mathrm{Nb}$ matrix, along with a partial reduction of the natural surface oxides, was observed upon a stepwise annealing up to $250{ }^{\circ} \mathrm{C}$. Nitrogen introduction to the system at $250^{\circ} \mathrm{C}$ promotes neither $\mathrm{N}$ diffusion into the $\mathrm{Nb}$ matrix nor the formation of new surface layers. Upon further heating to $500^{\circ} \mathrm{C}$ in a nitrogen atmosphere, the growth of a new subsurface $\mathrm{Nb}_{x} \mathrm{~N}_{y}$ layer was detected. These results shed light on the composition of the near-surface region of $\mathrm{Nb}$ after low-temperature nitrogen treatments, which are reported to lead to a performance enhancement of SRF cavities.
\end{abstract}

DOI: $10.1103 /$ PhysRevAccelBeams.22.103102

\section{INTRODUCTION}

Superconducting radio-frequency (SRF) cavities are the foundation of modern particle accelerators and freeelectron lasers (e.g., FLASH and EU-XFEL in Hamburg, Germany). Achieving higher accelerating gradients and better efficiency, as well as increasing their performance for continuous wave $(\mathrm{cw})$ operation provides several challenges ranging from fundamental science up to large-scale production [1-3]. Recently, thermal treatments performed at high $\left(800^{\circ} \mathrm{C}-900^{\circ} \mathrm{C}\right)$ and low $\left(120^{\circ} \mathrm{C}-160^{\circ} \mathrm{C}\right)$ temperatures and involving nitrogen presence were reported to improve the quality factor $\left(\mathrm{Q}_{0}\right.$ - the ratio of energy stored in a cavity to the energy lost per rf cycle) up to 3 times when compared with a regularly produced cavity $[2,3]$.

\footnotetext{
*Corresponding author.
}

Published by the American Physical Society under the terms of the Creative Commons Attribution 4.0 International license. Further distribution of this work must maintain attribution to the author(s) and the published article's title, journal citation, and DOI.
However, an understanding of the processes involved and the parameters required is still elusive.

As a type-II superconductor, niobium $(\mathrm{Nb})$ has the highest critical temperature and critical field among all pure elements. Combined with its resistance to corrosion and ductility, $\mathrm{Nb}$ has become the material of choice for SRF-based technology. The concentration of impurities (hydrogen, oxygen, nitrogen, and carbon) within the rf penetration layer $(\approx 40 \mathrm{~nm}$ for pure $\mathrm{Nb})$ is believed to be the key factor regarding the performance of cavities, either by lowering the electron mean-free path [4] and energy gap [5] or by trapping potential hydrogen which can cluster and precipitate niobium hydrides upon cooldown [6,7]. Traditionally, Nb-based SRF cavities were subjected to several production steps, including different polishing cycles like buffered chemical polishing (BCP) and electrochemical polishing (EP), as well as heat treatments at $800^{\circ} \mathrm{C}$ and $120^{\circ} \mathrm{C}[1,8]$ in a high vacuum in order to lower the hydrogen content inherent to the material [9]. In recent years, controlled annealing of SRF cavities in nitrogen atmospheres, at either high or low temperatures for 
different time spans, showed a decrease in their surface resistance [2,3]. The former treatment, known as nitrogen doping, includes annealing polycrystalline $\mathrm{Nb}$ cavities for a few minutes at $800^{\circ} \mathrm{C}$ in $3 \times 10^{-2}-8 \times 10^{-2}$ mbar of $\mathrm{N}_{2}$. Such treatment conditions lead to the formation of $\beta-\mathrm{Nb}_{2} \mathrm{~N}$ inclusions at the surface as well as promoting the growth of $\mathrm{NbO}[6,10]$. By etching approximately $5 \mu \mathrm{m}$ by $\mathrm{EP}$, therefore removing the aforementioned inclusions, cavities displayed record-breaking quality factors at intermediate accelerating field gradients up to $20 \mathrm{MV} / \mathrm{m}$. Another treatment, called nitrogen infusion, consists in annealing $\mathrm{Nb}$ cavities at $800^{\circ} \mathrm{C}$ for $3 \mathrm{~h}$ in a high vacuum $\left(10^{-7}-10^{-6} \mathrm{mbar}\right)$ followed by a decrease in temperature to the range $120^{\circ} \mathrm{C}-200^{\circ} \mathrm{C}$. Subsequently, nitrogen is injected at a pressure of $3 \times 10^{-2}$ mbar. The system is then kept in such conditions for $48 \mathrm{~h}$, yielding cavities with quality factors in the range of $6 \times 10^{10}$ and accelerating gradients up to $45 \mathrm{MV} \mathrm{m}^{-1}$ without the need of material removal [2]. Low-temperature annealing of $\mathrm{Nb}$ cavities under a $\mathrm{N}_{2}$ atmosphere is therefore an intense topic of research, since operation at high accelerating gradients $\left(>25 \mathrm{MV} \mathrm{m}^{-1}\right)$ with high $\mathrm{Q}_{0}$ are necessary for potential upgrades of existing accelerators into $\mathrm{cw}$ operation, like the European X-ray free-electron laser (EU-XFEL), as well as the development of future particle accelerator projects. However, insights on the actual surface state during and after such treatments are lacking. Ideally, the knowledge obtained from model systems (e.g., single-crystal surfaces) can potentially be applied to real cavity materials and eventually lead to the discovery of new cavity treatments that will improve the performance limits.

Most of the studies found in the literature address $\mathrm{N}$ and $\mathrm{Nb}$ interactions at high temperatures [11-14]. Nonetheless, few reports detail investigations of $\mathrm{Nb}$ single crystals under low $\mathrm{N}_{2}$ pressures and of cavity-grade $\mathrm{Nb}$ after undergoing real cavity-treatment conditions. Exposure of an oxide-free $\mathrm{Nb}(100)$ surface to $\mathrm{N}_{2}$ pressures in the range $7 \times 10^{-8}-7 \times 10^{-7}$ mbar at around $345^{\circ} \mathrm{C}$ leads to the formation of a $\mathrm{NbN}(100)$ epitaxial layer, while exposure at room temperature formed $\mathrm{NbN}$ clusters at the surface [15]. For polycrystalline cavity-grade $\mathrm{Nb}$, nanoscale niobiumnitride islands were reported after heat treatments between $120^{\circ} \mathrm{C}$ and $160^{\circ} \mathrm{C}$ with a $\mathrm{N}_{2}$ pressure of $\sim 3 \times 10^{-2}$ mbar, while photoelectron measurements displayed the presence of $\mathrm{NbN}_{(1-x)} \mathrm{O}$ below the natural oxide layer. Secondary ion mass spectrometry (SIMS) measurements revealed a diffusion of oxygen species for $\sim 20 \mathrm{~nm}$, while nitrogen diffused $\sim 50 \mathrm{~nm}$, having the highest concentration in the first few nanometers when the exposure temperature was $140^{\circ} \mathrm{C}$ [16], which, however, contradicts the bulk diffusion lengths of oxygen in $\mathrm{Nb}$ reported in the literature [17]. In order to obtain further detailed crystallographic information about the near-surface dissolution of nitrogen and oxygen in pure $\mathrm{Nb}$, we have investigated single crystals. By using such well-defined crystals, we address the intrinsic properties of $\mathrm{Nb}$, which will be modified by the presence of large-angle grain boundaries and other defects as present in real rf cavity material. Nevertheless, the results of our study on more idealized samples will add to our basic understanding of niobium's properties and serve as input for future studies on polycrystalline materials.

In this study, we investigated in and ex situ the effects of the recently proposed nitrogen infusion treatment in the near-surface region of $\mathrm{Nb}$ as well as the effect of stepwise annealing in UHV up to $500^{\circ} \mathrm{C}$ in a nitrogen atmosphere by means of $\mathrm{x}$-ray reflectivity (XRR), $\mathrm{x}$-ray photoemission spectroscopy (XPS), high-energy grazing-incidence diffuse $\mathrm{x}$-ray scattering (GIXRD), and scanning electron microscopy (SEM). High-photon-energy experiments facilitated the monitoring of changes within the few-nanometer to submicron depth from the surface. A gradual dissolution of $\mathrm{Nb}_{2} \mathrm{O}_{5}, \mathrm{NbO}_{2}$, and $\mathrm{NbO}$ layers at the surface upon annealing, followed by oxygen diffusion into $\mathrm{Nb}$, allied with the lack of evidence of nitrogen diffusion in infusion and higher-temperature treatment is discussed.

\section{EXPERIMENTAL METHODS}

\section{A. Samples}

Mechanically polished niobium (100) samples (10 mm diameter, $2 \mathrm{~mm}$ height) oriented to better than $0.1^{\circ}$ were employed for this study. Unless stated otherwise, the samples were annealed at $2000^{\circ} \mathrm{C}$ for $6 \mathrm{~h}$ by induction heating in an ultrahigh vacuum (UHV) at a starting pressure of $\sim 10^{-10}$ mbar and unavoidably exposed to air for several days before the experiments. This procedure ensures that the $\mathrm{Nb}$ single crystals are as clean as possible in the bulk.

\section{B. Characterization techniques and experimental setups}

A four-circle and a six-circle [18-20] diffractometer with Mo- $\mathrm{K}_{\alpha}$ and $\mathrm{Cu}-\mathrm{K}_{\alpha}$ sources, respectively, were employed for in situ x-ray reflectivity measurements of the $800^{\circ} \mathrm{C}$ annealed and nitrogen-infused samples. The stepwise annealing of the specimens was carried out at beam line ID31 at the European Synchrotron Radiation Facility (ESRF) in Grenoble, France, and followed by in situ high-energy GIXRD and XRR measurements using a photon energy of $70 \mathrm{keV}$, while the data were collected using two separate 2D pixel detectors. The use of high photon energies provides fast access to large areas in reciprocal space, excluding the need of a time-consuming sample and detector movements $[21,22]$.

For all aforementioned studies, the samples were mounted in a dedicated UHV setup, allowing direct measurements at different temperatures and gas conditions. The chamber has a cylindrical beryllium window and is connected to a pumping system capable of reaching base pressures of $\sim 10^{-8}$ mbar without bakeout. The sample is heated by a tungsten filament (see Fig. 1) typically 
achieving pressures of $\sim 10^{-7} \mathrm{mbar}$ at $800^{\circ} \mathrm{C}$. For all experiments involving the presence of nitrogen, nitrogen gas (99.999\% purity) was inserted in the chamber through a leak valve until the system reached a pressure of $3.3 \times 10^{-2}$ mbar, after which all the valves were closed and the chamber was kept under a static nitrogen atmosphere.

Oxygen and nitrogen, residing at interstitial crystallographic sites in the $\mathrm{Nb}$ lattice, give rise to distinct $\mathrm{x}$-ray diffuse scattering peaks by locally distorting the host lattice [23]. The concentration of these interstitials scales linearly with the diffusely scattered x-ray intensities. Because of refraction and absorption effects, the x-ray penetration into the $\mathrm{Nb}$ crystal is finite. When the incident angle $\alpha_{i}$ of the $\mathrm{x}$-ray beam with respect to the surface is aligned from close to the critical angle for total external reflection, $\alpha_{c}$, up to several times this value, the $\mathrm{x}$-ray penetration can be steered from several nanometers up to micrometers [24]. The value of $\alpha_{c}$ depends on the electron density of the crystal and the x-ray energy. For the experiments presented here, $\alpha_{c}=0.045^{\circ}$, which puts stringent demands on the stability and precision of the diffractometer [22]. In a symmetric way, the exit angle of the scattered $x$ rays also defines the penetration depth. In a GIXRD experiment, depth-resolved information is thus obtained by tuning the incident and exit angles of $\mathrm{x}$ rays whereby the so-called scattering depth $\Lambda[25,26]$ is set. The experimental setup in grazing-incidence geometry is depicted in Fig. 1. X rays impinge on the surface of the sample under an incident angle $\alpha_{i}$, and the diffracted signals are recorded by a large

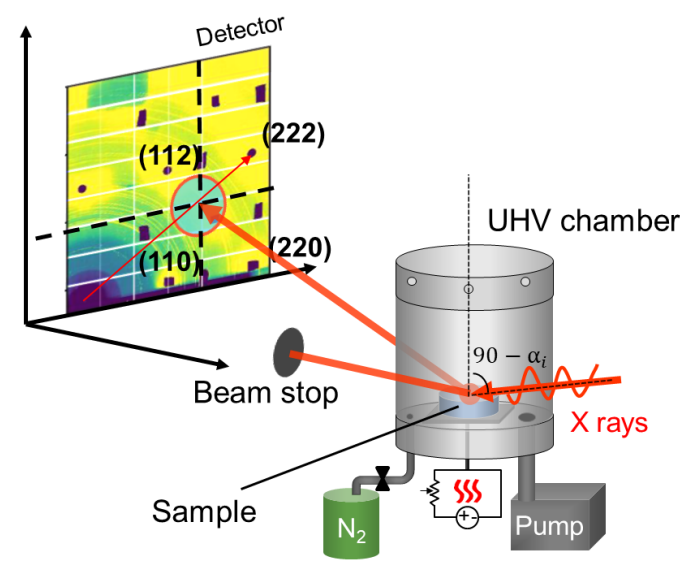

FIG. 1. Schematic of the GIXRD setup. The high-energy x-ray beam falls on the sample surface at grazing incident angle $\alpha_{i}$, and the diffraction patterns are obtained by a $2 \mathrm{D}$ detector while the sample undergoes different annealing treatments under UHV and $\mathrm{N}_{2}$. The blue circle represents the position of the interstitial diffuse scattering along the [111] direction (red line), while $\mathrm{Nb}$ reflections, indexed by their $h k l$ values, are blocked with lead pieces to locally protect the detector. In order to sample 3D reciprocal space, the sample is typically rotated around its surface normal (dashed line), and at each angular position a diffraction pattern is recorded.
2D detector. Locally, the detector is shielded by lead $(\mathrm{Pb})$ for the intense Bragg reflections of bulk $\mathrm{Nb}$ in order to avoid overexposure and damage.

XPS measurements were carried out separately using a lab-based system with monochromatic $\mathrm{AlK}_{\alpha}$ radiation, and the spectra were recorded in fixed transmission mode with an energy resolution of $0.4 \mathrm{eV}$ [20]. A high-resolution field-emission SEM was employed to characterize the surface morphology of the specimens.

\section{RESULTS AND DISCUSSION}

\section{A. $800{ }^{\circ} \mathrm{C}$ anneal in UHV}

During standard cavity preparation, an $800{ }^{\circ} \mathrm{C}$ annealing in a high vacuum is performed for a few hours to lower the inherent hydrogen content in the material acquired during manufacturing $[1,27]$. The presence of hydrogen can lead to the formation of niobium hydrides at the cavity surface, especially during the cooldown phase, leading to a poor performance [9]. A comparison between in situ XRR measurements of an "as-received" sample (without prior annealing) at room temperature and after $800^{\circ} \mathrm{C}$ annealing for $1 \mathrm{~h}$ at $10^{-7}$ mbar as well as the derived electron density profiles are shown in Figs. 2(a) and 2(b), respectively. At room temperature, the natural oxide layer can be described best (from surface to the metal-oxide interface) using a three-layer model composed of $\mathrm{Nb}_{2} \mathrm{O}_{5}, \mathrm{NbO}_{2}$, and $\mathrm{NbO}$, with individual thicknesses of $2.90,0.60$, and $1.20 \mathrm{~nm}$, respectively (error bar of $\pm 0.1 \mathrm{~nm}$ ) [28]. The total thickness of the natural oxide layer is $4.71 \mathrm{~nm}$, while the roughness varies from 0.2 to $0.4 \mathrm{~nm}$ for the oxide-metal interfaces while being close to $1.25 \mathrm{~nm}$ for the vacuum$\mathrm{Nb}_{2} \mathrm{O}_{5}$ interface. After annealing to $800^{\circ} \mathrm{C}$, both $\mathrm{Nb}_{2} \mathrm{O}_{5}$ and $\mathrm{NbO}_{2}$ layers reduced completely in favor of a $1.03-\mathrm{nm}$ thick $\mathrm{NbO}$ layer, while the interface roughness between $\mathrm{NbO}$ and $\mathrm{Nb}$ increased to $0.82 \mathrm{~nm}$.

It is important to note here that the surface of $\mathrm{Nb}$ is not oxide-free after such an annealing, in contrast to what is reported in Ref. [2], but a NbO layer remains at the surface. A simulated oxide-free $\mathrm{Nb}$ surface is shown in Fig. 2(a), with clearly visible differences when compared to the collected data after annealing to $800^{\circ} \mathrm{C}$. Similar effects were observed for XRR measurements with the $\mathrm{Nb}(110)$ surface, where $\mathrm{NbO}$ was the only natural oxide remaining after annealing at $300^{\circ} \mathrm{C}$ in UHV for 50 min, forming an epitaxial (111)-oriented $\mathrm{NbO}$ layer [28]. The transition from $\mathrm{Nb}_{2} \mathrm{O}_{5} / \mathrm{NbO}_{2} / \mathrm{NbO}$ upon annealing into $\mathrm{NbO}$ was also previously confirmed by XPS characterization [28]. Moreover, Auger spectroscopy revealed that clean $\mathrm{Nb}$ surfaces could be achieved only after annealing from $1800^{\circ} \mathrm{C}$ to $2000^{\circ} \mathrm{C}$ [29], in agreement with the high-resolution STM studies of similarly prepared $\mathrm{Nb}$ surfaces [30].

For the (100) surface, XPS measurements on singlecrystalline $\mathrm{Nb}$ etched by $\mathrm{BCP}$ and annealed at around $155^{\circ} \mathrm{C}$ and $265^{\circ} \mathrm{C}$ in UHV showed predominantly a 
(a)
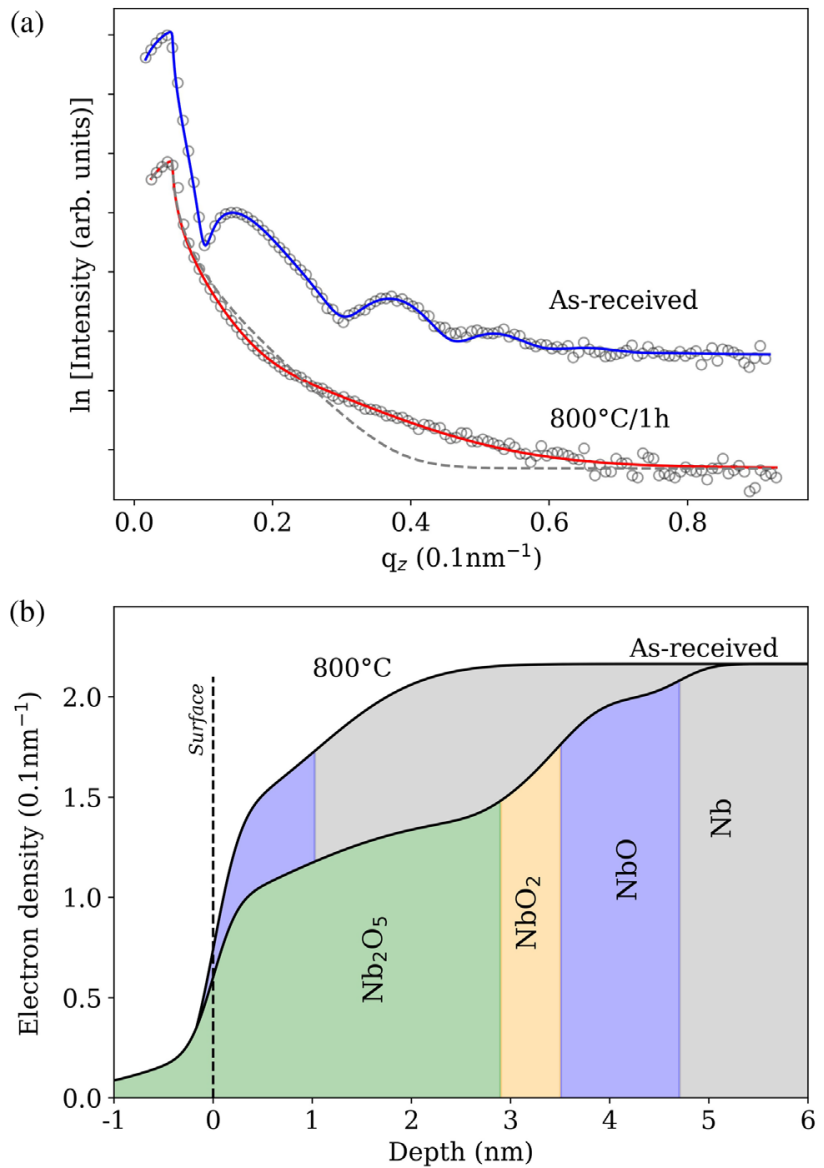

FIG. 2. (a) X-ray reflectivity data measured with $\mathrm{Mo} \mathrm{K}_{\alpha}$ radiation (open circles) with respective fits (solid lines) for a $\mathrm{Nb}(100)$ single crystal as received and after $800^{\circ} \mathrm{C}$ annealing in UHV for $1 \mathrm{~h}$. The dashed line represents the simulated curve for a $\mathrm{Nb}$ surface without any surface oxide and with a constant background. The scans are offset in the $y$ direction for better visibility. (b) Electron-density profiles for both sets of data obtained from the fits.

transition from $\mathrm{Nb}_{2} \mathrm{O}_{5}$ and $\mathrm{NbO}_{2}$ to $\mathrm{Nb}_{x} \mathrm{O}(0.4<x<2)$, together with an increase in surface roughness [31]. Furthermore, the presence of epitaxial $\mathrm{NbO}$ was confirmed by means of GIXRD for cavity-grade $\mathrm{Nb}$ (100) specimens annealed at $900^{\circ} \mathrm{C}$ in a high vacuum and treated with nitrogen at the same temperature [10].

Knowing that the release of oxygen by $\mathrm{Nb}$ in UHV does not occur below $1600{ }^{\circ} \mathrm{C}$ [17], it can be concluded that the available oxygen from the partially dissolved natural oxide layer diffuses into the $\mathrm{Nb}$ matrix. As will be shown later, for lower annealing temperatures, oxygen diffusion into $\mathrm{Nb}$ was confirmed by grazing-incidence $\mathrm{x}$-ray diffuse scattering measurements, similar to what was observed for the (110) surface [28].

\section{B. Nitrogen infusion}

In order to achieve high quality factors $\left(Q_{0} \sim 6 \times 10^{10}\right)$ with accelerating gradients up to $45 \mathrm{MV} \mathrm{m}^{-1}$, cavities are subjected to the so-called infusion process, which consists of the aforementioned $800^{\circ} \mathrm{C}$ anneal in a high vacuum followed by a decrease in the temperature to $120^{\circ} \mathrm{C}$, at which point nitrogen was introduced into the system, maintaining a constant pressure of $3.3 \times 10^{-2}$ mbar (25 mTorr) for $48 \mathrm{~h} \mathrm{[2].} \mathrm{Figures} \mathrm{3(a)} \mathrm{and} \mathrm{3(b)} \mathrm{show} \mathrm{in} \mathrm{situ}$ XRR data measured at each step of the infusion treatment as well as the fitted electron density profiles. At room temperature, before the treatment, the surface displays a similar configuration to the "as-received" sample, with the natural oxides following the order $\mathrm{Nb}_{2} \mathrm{O}_{5}, \mathrm{NbO}_{2}$, and $\mathrm{NbO}$ from the surface to the metal-oxide interface. Individual thicknesses of 1.27, 0.17, and $1.14 \mathrm{~nm}$ for $\mathrm{Nb}_{2} \mathrm{O}_{5}, \mathrm{NbO}_{2}$, and $\mathrm{NbO}$, respectively, were extracted from the fit. All interfaces showed roughness between 0.1 and $0.4 \mathrm{~nm}$. All fits of this sample show a discrepancy in the first few data points due to the surface curvature and faceting

(a)
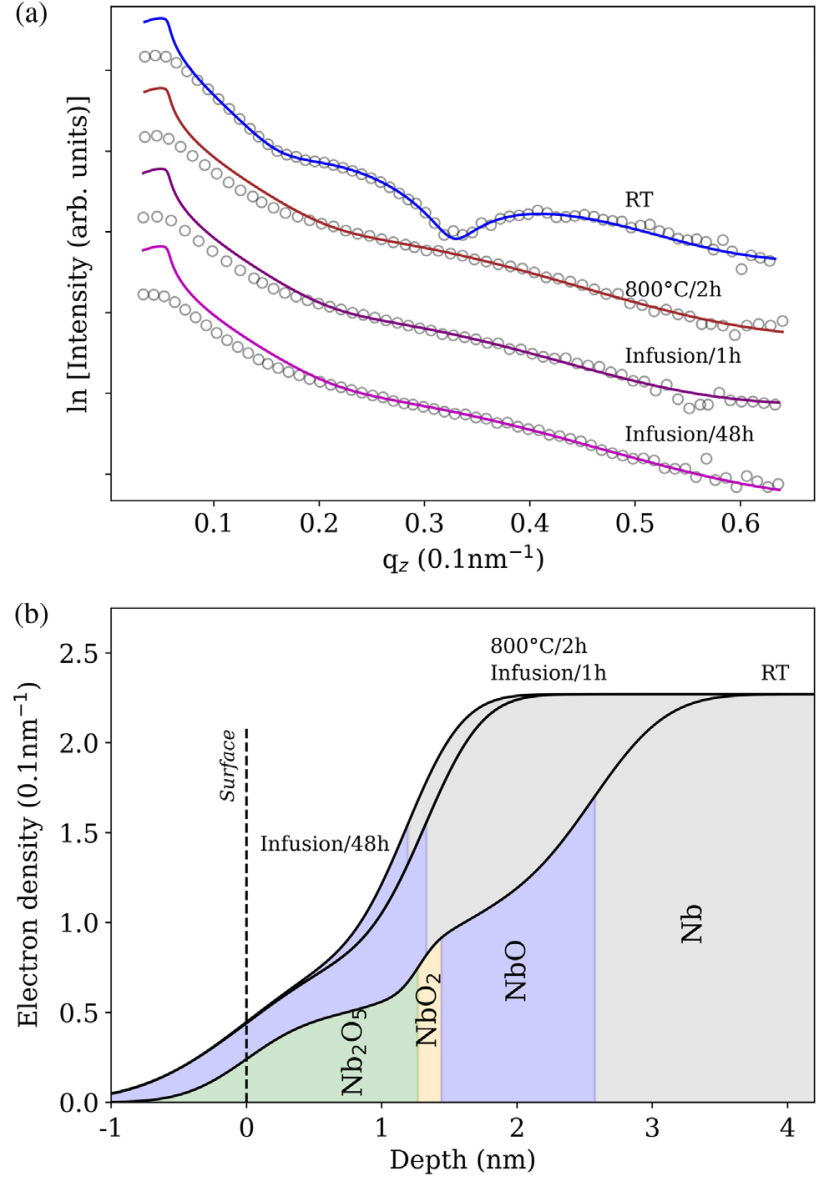

FIG. 3. (a) X-ray reflectivity data measured with $\mathrm{CuK}_{\alpha}$ radiation (open circles) with respective fits (solid lines) for various steps of the infusion procedure. The sample curvature compromises the fit in the first few data points. The scans are offset in the $y$ direction for better visibility. (b) Electron density profiles for each step. The extracted densities are lower than the expected bulk values for the niobium oxides and metallic niobium due to the pronounced sample curvature. 
caused by the $2000^{\circ} \mathrm{C}$ anneal performed prior to the $\mathrm{x}$-ray experiments [32].

Upon annealing at $800^{\circ} \mathrm{C}$ for $2 \mathrm{~h}$, similar to the previous results, the surface was composed of a single $\mathrm{NbO}$ layer with a thickness of $1.33 \mathrm{~nm}$ and slightly superior interface roughness in the range $0.3-0.6 \mathrm{~nm}$. While the sample was kept at $120^{\circ} \mathrm{C}$, nitrogen was inserted in the chamber until the pressure reached $3.3 \times 10^{-2}$ mbar. The chamber valves were then closed, keeping a static nitrogen pressure. The XRR measurements were performed continuously during the total treatment duration $(48 \mathrm{~h})$; however, few differences were observed between the curves. After $1 \mathrm{~h}$ of nitrogen treatment, the XRR curves were essentially identical to the curves obtained after annealing at $800^{\circ} \mathrm{C}$ for $2 \mathrm{~h}$. The surface still displayed only a $\mathrm{NbO}$ layer with a thickness of $1.33 \mathrm{~nm}$. After $48 \mathrm{~h}$ in a nitrogen atmosphere, the thickness of the $\mathrm{NbO}$ layer decreased to $1.20 \mathrm{~nm}$ with similar interfacial roughness as the previous step, between 0.3 and $0.6 \mathrm{~nm}$.

Interestingly, no evidence for either a nitrogen-rich or a nitride layer was observed with prolonged exposure of the $\mathrm{Nb}$ specimen to a nitrogen atmosphere at $120^{\circ} \mathrm{C}$, but rather only the progressive dissolution of the remaining $\mathrm{NbO}$ layer at the surface. For thin heteroepitaxial films, it is known that a passivating layer of $\mathrm{NbO}$ can be achieved after oxidation of $\mathrm{Nb}$ at $340^{\circ} \mathrm{C}$ in a low-pressure dry oxygen atmosphere [33], which could in this case hinder nitrogen diffusion. Such a passivating layer was not present in the sample under test, as confirmed by the regrowth of the oxides $\mathrm{NbO}_{2}$ and $\mathrm{Nb}_{2} \mathrm{O}_{5}$ after it was reexposed to air. Moreover, in contrast to what was observed for cavitygrade $\mathrm{Nb}$ upon high-temperature annealing, where rectangular- and triangular-shaped precipitates were observed at the surface $[10,14]$, no precipitates were detected by SEM after infusion [see Fig. S1(a) in Supplemental Material [34]]. This indicates that the initial material purity may also play a role in the formation of such features on the surface.

Although SIMS measurements are difficult when dealing with nitrogen, as well as suffering from an inability to define the exact location of the oxide-metal interface [35], nitrogen incorporation in $\mathrm{Nb}$ after exposure to $3.3 \times 10^{-2}$ mbar nitrogen at $120^{\circ} \mathrm{C}[2,16]$ was reported. The reported concentrations should have been easily detectable by XRR measurements. One hypothesis to explain such discrepancies is the absence of grain boundaries in the samples studied in this work, which could act as enhanced diffusion sites for nitrogen atoms [36]. XPS results from the $\mathrm{Nb} 3 \mathrm{~d}$ core level for polycrystalline $\mathrm{Nb}$ subjected to annealing cycles of $800^{\circ} \mathrm{C}$ for $3 \mathrm{~h}$ in a high vacuum followed by $48 \mathrm{~h}$ at $140{ }^{\circ} \mathrm{C}$ with a nitrogen pressure of $3.3 \times 10^{-2}$ mbar were interpreted as displaying $\mathrm{NbN}_{(1-x)} \mathrm{O}_{x}$ at a peak position of $203.2 \mathrm{eV}$ [16]. Such a peak was also attributed by other authors [37,38] as belonging to $\mathrm{NbC}$ as well as $\mathrm{NbO}$; therefore, an analysis of the $\mathrm{C} 1 \mathrm{~s}, \mathrm{~N} \mathrm{1s}$, and $\mathrm{O} 1 \mathrm{~s}$ core levels is necessary to understand the system fully. This is presented below.

\section{Stepwise annealing and interstitial x-ray diffuse scattering}

Interstitial atoms, such as oxygen and nitrogen, can occupy octahedral sites in the $\mathrm{Nb}$ bcc lattice $[39,40]$. Together with the natural mechanical instability along the [111] direction of the lattice leading to the $\omega$ phase [39,41], oxygen- and nitrogen-induced local distortions can produce diffuse scattering maxima at the reduced scattering vector $q^{*}=\frac{2}{3}\left(\begin{array}{lll}1 & 1 & 1\end{array}\right)$ and space group Im-3m symmetry equivalent places in reciprocal space [23]. This diffracted intensity, in a regime of random defect concentration, can be written as [42]

$$
I_{D} \propto c(1-c) S(\boldsymbol{Q})
$$

where $c$ is the concentration of the defect which is responsible for the intensity while $S(\boldsymbol{Q})$ is the square of the scattering amplitude of a single defect.

Contrary to the (110) surface, where the [111] direction resides in plane, for the (100) surface the diffuse maxima has an out-of-plane component. This makes the tuning of the x-ray exit angle impossible during the experiment. However, the probed depth can still be changed by modifying the x-ray incidence angle. Taking into account the sample curvature, it is possible to calculate an effective scattering depth $\left(\Lambda_{\text {eff }}\right)$ for each measured step [24].

The evolution of the diffuse intensity was followed in situ during stepwise annealing in UHV $\left(10^{-8}\right.$ mbar $)$ as well as in a nitrogen atmosphere. Starting from room temperature (RT), the sample was annealed at $120^{\circ} \mathrm{C}$, $200^{\circ} \mathrm{C}$, and $250^{\circ} \mathrm{C}$, sequentially. At $250^{\circ} \mathrm{C}$, nitrogen was inserted into the chamber until the pressure reached $3.3 \times 10^{-2}$ mbar. Similar to the previous experiments, the $\mathrm{N}_{2}$ atmosphere was kept under static conditions. Furthermore, the sample temperature was increased to $500{ }^{\circ} \mathrm{C}$ in the $\mathrm{N}_{2}$ atmosphere as a last annealing step before air exposure. Together with diffuse scattering measurements, XRR curves were obtained for each temperature, providing information about the surface oxides. Table I summarizes the annealing temperatures and times at each step.

The thickness and roughness of the oxide layers during each step of annealing are presented in Fig. 4, while Fig. 5 shows the related in situ XRR curves and respective electron-density profiles extracted. The natural oxide layer was composed, beginning at the surface and ending at the metal-oxide interface, of $\mathrm{Nb}_{2} \mathrm{O}_{5}, \mathrm{NbO}_{2}$, and $\mathrm{NbO}$. The outermost oxide, $\mathrm{Nb}_{2} \mathrm{O}_{5}$, gradually decreased in thickness upon annealing up to $200^{\circ} \mathrm{C}$ and vanished at $250{ }^{\circ} \mathrm{C}$. Until $200^{\circ} \mathrm{C}, \mathrm{NbO}_{2}$ followed the same trend as $\mathrm{Nb}_{2} \mathrm{O}_{5}$. However, upon further annealing it experiences a slight increase in thickness of about $0.09 \mathrm{~nm}$, remaining almost constant thereafter. Hardly affected by annealing at $120^{\circ} \mathrm{C}, \mathrm{NbO}$ 
TABLE I. Temperature, total time, and fitted decay lengths obtained by grazing incidence diffuse scattering measurements.

\begin{tabular}{lcc}
\hline \hline Temperature $\left({ }^{\circ} \mathrm{C}\right)$ & Total time $($ hh:min) & Decay length $(\mathrm{nm})$ \\
\hline $\mathrm{RT}$ & $\ldots$ & 0.969 \\
120 & $13: 45$ & 0.989 \\
200 & $14: 00$ & 1.970 \\
250 & $15: 20$ & 2.713 \\
$250+\mathrm{N}_{2}$ & $14: 20$ & 3.576 \\
$500+\mathrm{N}_{2}$ & $10: 00$ & $\ldots{ }^{\mathrm{a}}$ \\
\hline \hline
\end{tabular}

${ }^{\mathrm{a}}$ Diffuse scattering measurements for the $500^{\circ} \mathrm{C}+\mathrm{N}_{2}$ annealing step are not discussed.

grows at the expense of the other oxides after annealing at $200^{\circ} \mathrm{C}$ and starts to dissolve upon further annealing. The substrate roughness is barely affected by annealing at $120^{\circ} \mathrm{C}$ and shows a steady growth as the temperature is increased. The stepwise dissolution of the natural oxides was also observed for the $\mathrm{Nb}(110)$ surface by both XPS and $\mathrm{XRR}$ measurements [28]. For the (110) surface, $\mathrm{Nb}_{2} \mathrm{O}_{5}$ dissolves faster than the other oxides $\left(\mathrm{NbO}_{2}\right.$ and $\left.\mathrm{NbO}\right)$ at the surface, with its layer thickness decreasing $\sim 0.23 \mathrm{~nm}$ after annealing for $5 \mathrm{~h}$ in UHV at $145^{\circ} \mathrm{C}$. On the other hand, as shown here, $\mathrm{NbO}_{2}$ is consumed faster on the (100) surface, with a thickness decrease of $\sim 0.22 \mathrm{~nm}$.

The behavior of the natural oxides proposed here is similar to what was observed in STM studies of the (100) surface, for which a reduction from $\mathrm{Nb}_{2} \mathrm{O}_{5}$ to $\mathrm{NbO}_{2}$ was observed in the form of a ladderlike structure caused by oxygen segregation at the surface during annealing at $580^{\circ} \mathrm{C}$ in UHV with subsequent regrowth of $\mathrm{Nb}_{2} \mathrm{O}_{5}$ after air exposure [43].

After $\mathrm{N}_{2}$ exposure, no new nitride or nitrogen-rich layer was observed at $250{ }^{\circ} \mathrm{C}$, and the dissolution of the natural oxides has virtually stopped. However, at $500^{\circ} \mathrm{C}$ a new layer with a thickness of $1.41 \mathrm{~nm}$ was formed between $\mathrm{NbO}$

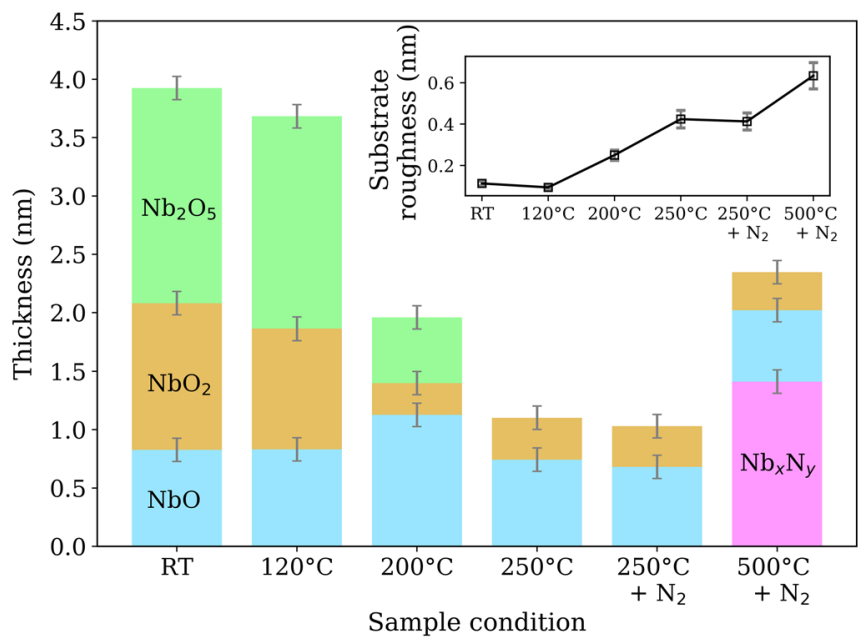

FIG. 4. Thickness and substrate roughness (inset) obtained by XRR in each step of the sample treatment. and $\mathrm{Nb}$. The electron density of this layer is similar to the theoretically calculated value for the $\beta-\mathrm{Nb}_{2} \mathrm{~N}$ phase, which is known to precipitate upon high-temperature treatments in a $\mathrm{N}_{2}$ atmosphere $[10,14]$. Therefore, it can be concluded that the layer relates to the presence of a possible $\mathrm{Nb}_{x} N_{y}$ compound underneath the oxide layer, as the presence of typical $\beta-\mathrm{Nb}_{2} \mathrm{~N}$ precipitates at the surface was not observed by SEM [Fig. S1(b) in Supplemental Material [34]].

(a)
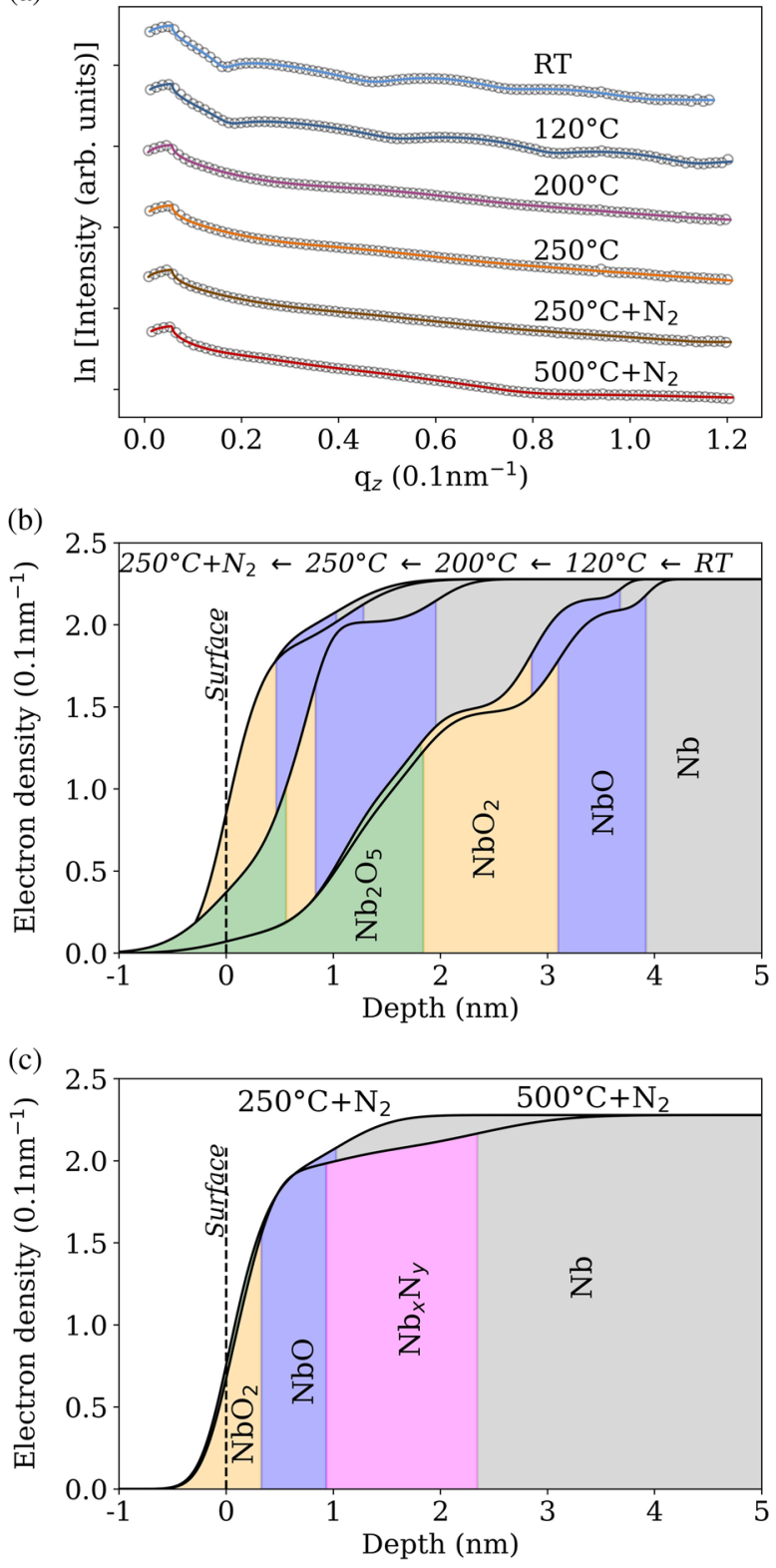

FIG. 5. (a) X-ray reflectivity data (open circles) measured with photon energies of $70 \mathrm{keV}$ with the respective fits (solid lines). The scans are offset in the $y$ direction. (b) Electron-density profiles obtained from the fits for the data collected from RT up to the addition of $\mathrm{N}_{2}$ at $3.33 \times 10^{-2}$ mbar at $250^{\circ} \mathrm{C}$. (c) Comparison between the electron density profiles obtained at $250^{\circ} \mathrm{C}$ and $500{ }^{\circ} \mathrm{C}$ in a $\mathrm{N}_{2}$ atmosphere. 
During the high-energy GIXRD measurements, the sample is rotated around the $\mathrm{Nb}$ surface normal over $20^{\circ}$ whereby the $\mathrm{Nb} h h l$ plane is swept through the Ewald sphere. The resulting diffraction patterns, obtained at different temperatures, are displayed in Fig. 6 for a fixed incident angle of $0.04^{\circ}$, corresponding to a scattering depth $\Lambda_{\text {eff }}$ of $\sim 100 \mathrm{~nm}$. The detector is locally shielded by lead pieces at the strong $\mathrm{Nb}$ Bragg peak positions, which are labeled according to their $h k l$ coordinates. Some powder rings from the beryllium window of the vacuum chamber are also visible. In between the $\mathrm{Nb}$ Bragg peaks, distinct diffuse scattering intensity is present. Close to the Bragg peaks, mostly thermal diffuse scattering (TDS) is observed, which grows in intensity with an increasing temperature. Oxygen and nitrogen interstitials give rise to pronounced diffuse scattering maxima near $\mathrm{Q}=\frac{4}{3}(111)$ (see also Fig. 1). Clearly, at $120^{\circ} \mathrm{C}$, the overall diffuse scattering is very pronounced, and this is related to the dissolution of the native oxide layer and subsequent formation of oxygen interstitials.

In order to retrieve the depth-resolved concentration of the interstitials in the sample, a region of interest around $\mathrm{Q}=\frac{4}{3}(111)\left(\Delta q_{x y}=\Delta q_{z}=0.42 \AA^{-1}\right)$ was analyzed in more detail. The integrated intensity in this area is evaluated as a function of the incident angle, which corresponds to a particular scattering depth $\Lambda_{\text {eff }}$. The resulting curve was fitted using an exponential decay model for the interstitial concentration such as

$$
c(z)=a e^{\left(-z-z_{0}\right) / \tau}+d, \quad \text { for } z<z_{0},
$$

where the fitted parameters are a preexponential factor $a$, giving the excess concentration at the interface, an exponential decay length $\tau$, and a final bulk concentration $d . z$ is the depth, with zero being the vacuum-oxide interface and $z_{0}$ the position of the metal-oxide interface. The values of $a$ and $d$ are concentrations given in terms of the ratio between the number of defects $N_{D}$ and the total number of atoms $N_{T}$. Thermal diffuse-scattering contributions as well as optical factors $[24,26]$ were also taken into account by the fitting routine.

Figure 7(a) shows the diffuse scattering data collected from RT up to $250^{\circ} \mathrm{C}$ in a $\mathrm{N}_{2}$ atmosphere. The interstitial concentration profile extracted from the fits is presented in Fig. 7(b). An increase in the decay length of subsurface oxygen, associated with a decrease of the initial concentration (at $z=0$ ), was observed as the temperature was increased, as seen in the inset in Fig. 7(b). This behavior can be understood as the progressive diffusion of oxygen liberated from the oxide layers, which in turn decrease in total thickness. Furthermore, as the temperature increases, the diffusion length of the liberated oxygen in $\mathrm{Nb}$ increases drastically. The interstitial concentration in the first $10 \mathrm{~nm}$ is the highest during annealing at $120^{\circ} \mathrm{C}$, which agrees with the $12 \mathrm{~nm}$ of calculated diffusion length of oxygen in pure $\mathrm{Nb}$ [17]. Compared to $120^{\circ} \mathrm{C}$, annealing at $200^{\circ} \mathrm{C}$ liberates more oxygen in the $\mathrm{Nb}$ matrix and enables it to diffuse
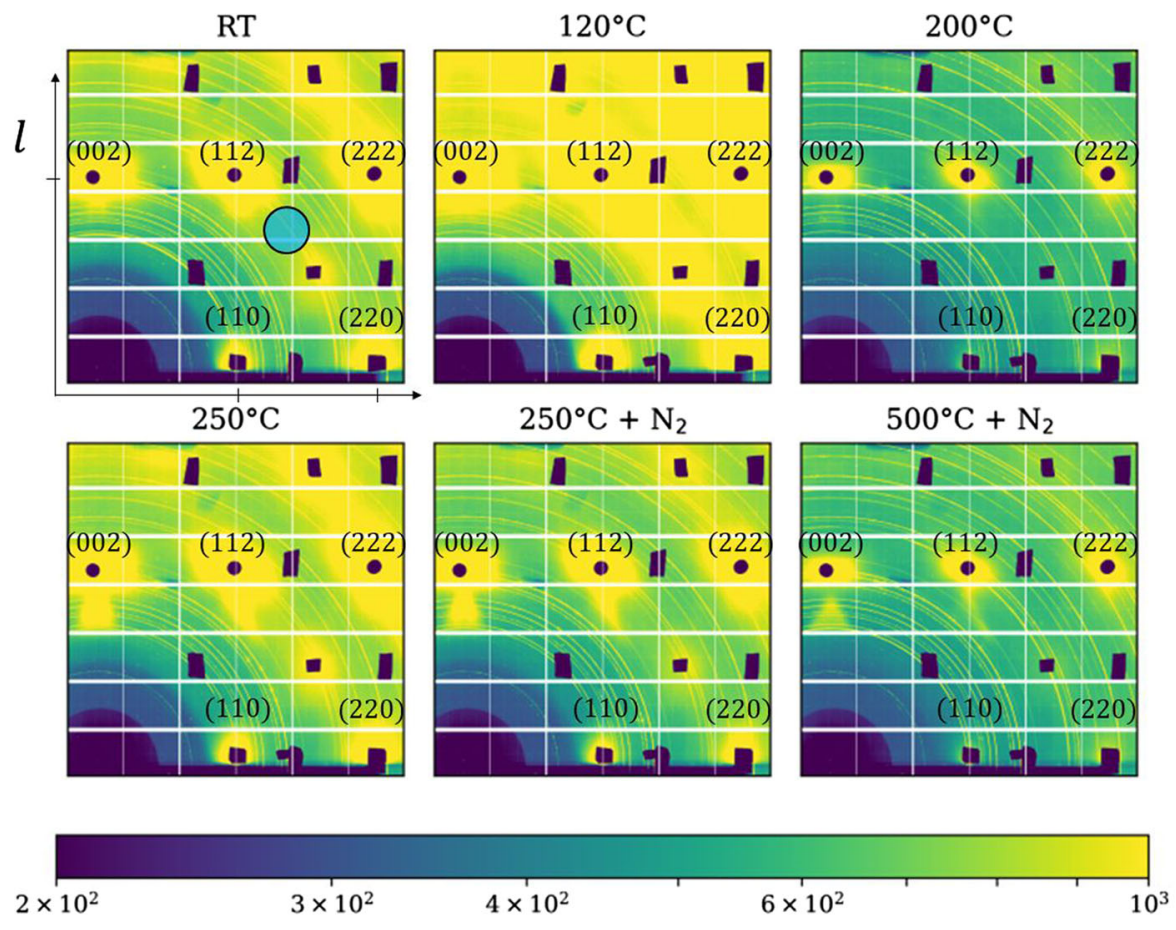

FIG. 6. Diffraction patterns obtained at different temperatures with an incident angle of $0.04^{\circ}$, corresponding to a scattering depth $\Lambda_{\text {eff }}$ of $\sim 100 \mathrm{~nm}$. At $120^{\circ} \mathrm{C}$, a clear increase in diffuse intensity is observed due to the presence of subsurface oxygen. Lead (Pb) pieces block the $\mathrm{Nb}$ Bragg peaks. Powder rings originating from the beryllium $(\mathrm{Be})$ windows of the chamber are also observed. The region of interest employed in the data analysis is schematically shown in blue (see the text for details). 
(a)

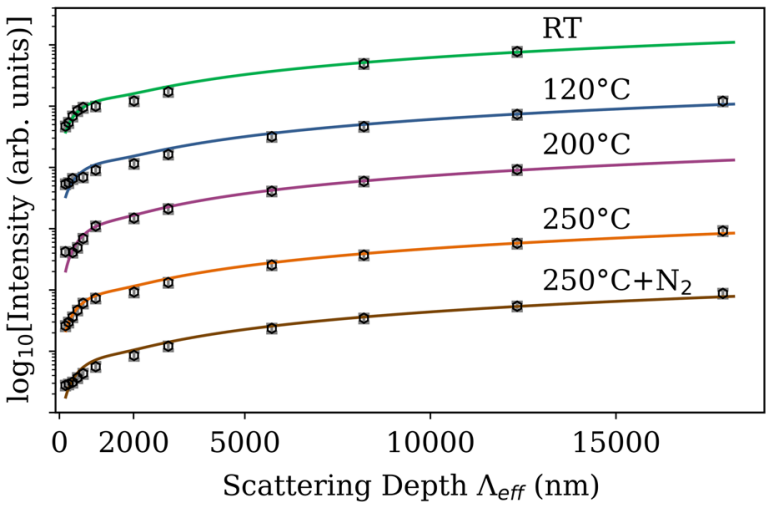

(b)

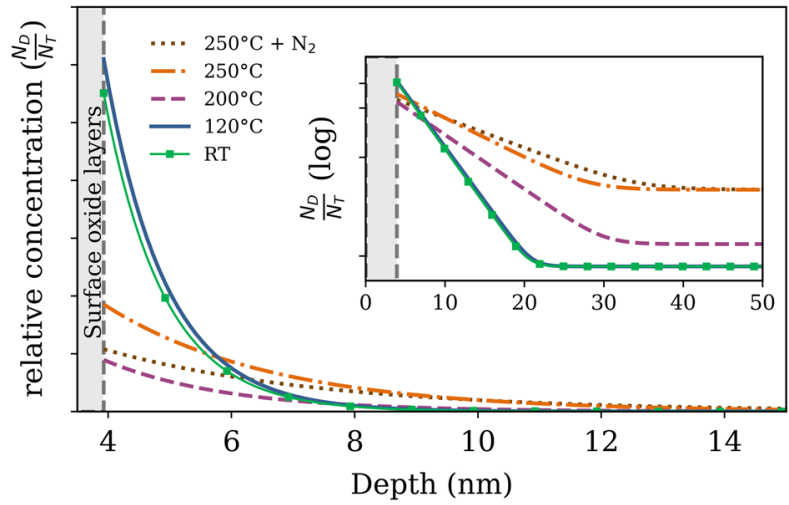

FIG. 7. (a) Diffuse scattering intensities obtained for each temperature step (squares) and the respective fit (solid line). The curves are offset in the $y$ direction. (b) Interstitial concentration obtained from the fit plotted in the linear scale and the concentration in the log scale (inset). The profiles are represented by connected squares (room temperature), solid $\left(120^{\circ} \mathrm{C}\right)$, dashed $\left(200^{\circ} \mathrm{C}\right)$, dot-dashed $\left(250^{\circ} \mathrm{C}\right)$, and dotted lines $\left(250^{\circ} \mathrm{C}\right.$ under a $\mathrm{N}_{2}$ atmosphere).

further. This is seen by the increase in the bulk concentration from $\sim 3 \times 10^{-9}$ to $\sim 3 \times 10^{-8}$ as well as the decaylength increase from 0.98 to $1.97 \mathrm{~nm}$. On the other hand, the subsurface concentration in the first tens of nanometers decreases. The same trend continued during annealing at $250^{\circ} \mathrm{C}$, increasing even more the decay length up to $2.71 \mathrm{~nm}$ and the bulk concentration to $\sim 5 \times 10^{-6}$. The total number of interstitials is determined by the availability of oxygen and nitrogen species. The XRR results indicate that the dissolution rate of the oxides has decreased considerably after the first annealing step to $250^{\circ} \mathrm{C}$, and it is concluded that this process has nearly ended. Therefore, the number of interstitials diffusing into the bulk from the near-surface region is higher than the influx from the surface. Hence, the interstitial concentration within the first few nanometers decreased, while the decay length increased to $3.57 \mathrm{~nm}$. The concentration in the large bulk reservoir remained essentially the same. This means that annealing in a $\mathrm{N}_{2}$ atmosphere at $250^{\circ} \mathrm{C}$ promoted only further diffusion of oxygen originating from the surface oxides into $\mathrm{Nb}$ with no evidence of nitrogen incorporation in the metallic $\mathrm{Nb}$ matrix. The corresponding decay lengths for different annealing steps are summarized in Table I.

High-resolution XPS measurements were performed after the sample was reexposed to air for 10 days. Deconvoluted XPS spectra of $\mathrm{Nb} 3 \mathrm{~d}$ observed for the normal, as well as the grazing-exit mode, are shown in Figs. 8(a) and 8(b), which confirm the regrowth of the natural oxide layers previously partially dissolved due to the stepwise UHV annealing. The characteristic doublets of metallic $\mathrm{Nb}$ are observed at the binding energies of 202.0 and $204.7 \mathrm{eV}$. The top surface oxide layer on $\mathrm{Nb}$ is consisting of $\mathrm{Nb}_{x} \mathrm{O}, \mathrm{NbO}, \mathrm{NbO}_{2}$, and $\mathrm{Nb}_{2} \mathrm{O}_{5}$, for which the binding energies exceed to metallic $\mathrm{Nb}$ by $0.7,1.9,3.0$, and $5.0 \mathrm{eV}$, respectively. A strong contribution from $\mathrm{NbC}$ is suggested by the presence of $3 d_{5 / 2}$ and $3 d_{3 / 2}$ peaks at
203.3 and $206.0 \mathrm{eV}$, respectively, and confirmed by the presence of a peak in $\mathrm{C} 1 \mathrm{~s}$ core level at $282.6 \mathrm{eV}$ assigned to the $\mathrm{Nb}-\mathrm{C}$ bond [44] (Fig. S2 in Supplemental Material [34]). Furthermore, a contribution from two peaks at binding energies of 204.3 and $207.0 \mathrm{eV}$ is detected, which can be attributed to a $\mathrm{NbN}_{x} \mathrm{O}_{y}$ phase, supported by the presence of a peak in $\mathrm{N} 1 \mathrm{~s}$ core level [Figs. 8(c) and 8(d)] at the binding energy of $\sim 397.5 \mathrm{eV}$, which corresponds to $\mathrm{Nb}$ bound to $\mathrm{N}$ in niobium nitrides and oxynitrides as reported for the nitrogen-doped niobium samples [10]. The peak at a higher binding energy in the $\mathrm{N} 1 \mathrm{~s}$ region at $\sim 400 \mathrm{eV}$ is assigned to the adsorbed $\mathrm{N}$ on the surface. The intensity of the lower binding energy peak in the $\mathrm{N} 1 \mathrm{~s}$ spectrum is

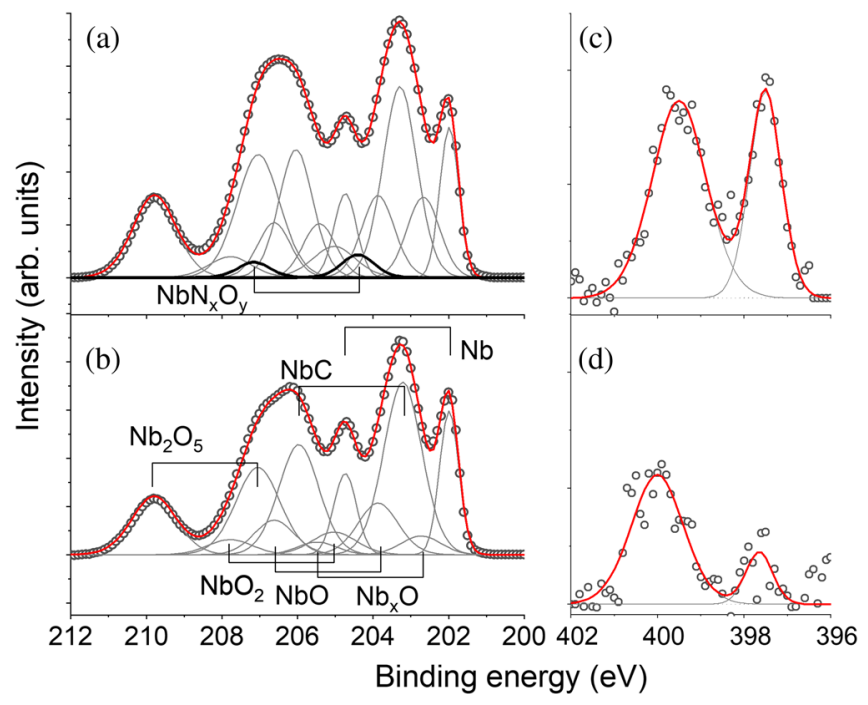

FIG. 8. Deconvolution of $\mathrm{Nb} 3 \mathrm{~d}$ and $\mathrm{N}$ 1s lines in normal exit mode (a),(c) and with a $70^{\circ}$ exit angle (b),(d). Phases corresponding to niobium, niobium oxides, and niobium carbides are represented in gray. Contributions from niobium nitrides are shown in black. 
significantly suppressed when measured at the grazing-exit angle given in Fig. 8(d), where the majority of detected photoelectrons correspond to the top surface layer. Moreover, the peaks corresponding to the $\mathrm{NbN}_{x} \mathrm{O}_{y}$ phase in the normal-exit $\mathrm{Nb} 3 \mathrm{~d}$ spectrum in Fig. 8(a) are not observable in the grazing-exit $\mathrm{Nb} 3 \mathrm{~d}$ spectrum in Fig. 8(b). These results indicate that the nitrogen-containing phase does not reside on the top layer but close to the oxide-metal interface, which is in line with the in situ XRR measurements on the same sample at $500^{\circ} \mathrm{C}$ in a nitrogen atmosphere.

\section{CONCLUSIONS}

The effect of different thermal treatments that have been recently applied to $\mathrm{Nb} \mathrm{SRF}$ cavities was studied in the nearsurface region of single-crystalline $\mathrm{Nb}(100)$. In situ XRR revealed that annealing to $800^{\circ} \mathrm{C}$ in UHV reduces the natural oxide layer composed of $\mathrm{Nb}_{2} \mathrm{O}_{5}, \mathrm{NbO}_{2}$, and $\mathrm{NbO}$ into solely $\mathrm{NbO}$; the natural oxide layer was observed to regrow after exposure to air. After a nitrogen exposure at $120^{\circ} \mathrm{C}$ and $3.3 \times 10^{-2}$ mbar, neither a nitrogen-rich layer nor interstitial nitrogen were detected. In situ high-energy $\mathrm{x}$-ray diffuse scattering combined with XRR measurements during stepwise annealing in UHV up to $250^{\circ} \mathrm{C}$ demonstrated that the partial dissolution of the natural oxides leads to the diffusion of oxygen into $\mathrm{Nb}$. At $120^{\circ} \mathrm{C}$, interstitial oxygen is mostly present within the first $10 \mathrm{~nm}$, while a temperature increase leads to further diffusion into the bulk. When the sample was exposed to $3.3 \times 10^{-2}$ mbar of $\mathrm{N}_{2}$ at $250^{\circ} \mathrm{C}$, no evidence of nitrogen presence either in the form of a nitrogen-containing layer or as interstitial nitrogen was detected. Annealing at $500^{\circ} \mathrm{C}$ resulted in the formation of a $\mathrm{Nb}_{x} \mathrm{~N}_{y}$ layer underneath the remaining $\mathrm{NbO}_{2}$ and $\mathrm{NbO}$ at

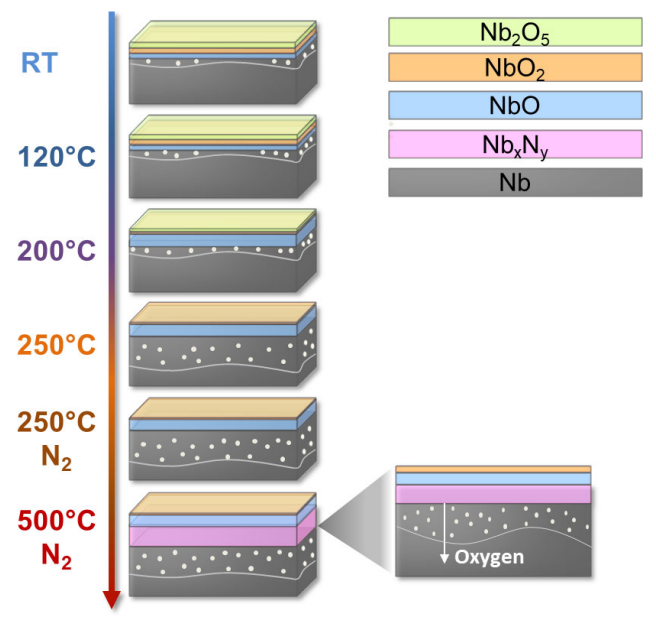

FIG. 9. Schematic representation of the stepwise annealing of $\mathrm{Nb}(100)$. The natural oxide layers gradually dissolve, and the liberated oxygen atoms diffuse into the $\mathrm{Nb}$ matrix. At $500{ }^{\circ} \mathrm{C}$ under a $\mathrm{N}_{2}$ atmosphere, a $\mathrm{Nb}_{x} \mathrm{~N}_{y}$ layer is formed underneath the remaining niobium oxides. the surface. A schematic representation of the stepwise procedure is shown in Fig. 9.

Ex situ photoelectron spectroscopy measurements confirm the presence of $\mathrm{Nb}-\mathrm{N}$ bonding as well as the regrowth of the natural oxide layer at the surface upon exposure to air. These results suggest that higher-temperature treatments (e.g., above $250^{\circ} \mathrm{C}$ ) are necessary for nitrogen to react effectively for the case of the ideal situation of ultrapure $\mathrm{Nb}$ single crystals, in line with $\mathrm{Nb}-\mathrm{N}$ thermodynamics. In turn, we may conclude that the nitrogeninduced increased performance of SRF cavities after low-temperature annealing is related to real cavity material properties such as grain boundaries and its higher level of impurities, such as carbon. A rearrangement of the oxygen interstitial profile takes place during the low-temperature annealing of $\mathrm{Nb}$ in a nitrogen atmosphere, which is suggested in the literature to be potentially partially responsible for cavity improvements [2]. Further studies concerning the effect of grain boundaries as well as other crystal orientations are recommended in order to elucidate the apparent improvement in the performance of SRF cavities subjected to low-temperature thermal treatments.

\section{ACKNOWLEDGMENTS}

SEM analysis by S. Kulkarni and A. Jeromin is acknowledged. The authors thank T. Meisner and A. Weible for the UHV-induction annealing of the $\mathrm{Nb}$ crystals at MPI for Intelligent Systems. G. D. L. S. and B. F. acknowledge the funding from BMBF Grant No. 05H15GURBB. G. D. L. S. thanks K. P. Furlan for the revision of the presented figures. The authors thank the ESRF for the granted beam time under Proposal No. HC-3244.

[1] D. Reschke, V. Gubarev, J. Schaffran, L. Steder, N. Walker, M. Wenskat, and L. Monaco, Performance in the vertical test of the 832 nine-cell $1.3 \mathrm{GHz}$ cavities for the European X-ray Free Electron Laser, Phys. Rev. Accel. Beams 20, 042004 (2017).

[2] A. Grassellino, A. Romanenko, Y. Trenikhina, M. Checchin, M. Martinello, O. S. Melnychuk, S. Chandrasekaran, D. A. Sergatskov, S. Posen, A. C. Crawford, S. Aderhold, and D. Bice, Unprecedented quality factors at accelerating gradients up to $45 \mathrm{MVm}-1$ in niobium superconducting resonators via low temperature nitrogen infusion, Supercond. Sci. Technol. 30, 094004 (2017).

[3] A. Grassellino, A. Romanenko, D. Sergatskov, O. Melnychuk, Y. Trenikhina, A. Crawford, A. Rowe, M. Wong, T. Khabiboulline, and F. Barkov, Nitrogen and argon doping of niobium for superconducting radio frequency cavities: a pathway to highly efficient accelerating structures, Supercond. Sci. Technol. 26, 102001 (2013).

[4] J. T. Maniscalco, D. Gonnella, and M. Liepe, The importance of the electron mean free path for superconducting radio-frequency cavities, J. Appl. Phys. 121, 043910 (2017). 
[5] M. Martinello, A. Grassellino, M. Checchin, A. Romanenko, O. Melnychuk, D. A. Sergatskov, S. Posen, and J.F. Zasadzinski, Effect of interstitial impurities on the field dependent microwave surface resistance of niobium, Appl. Phys. Lett. 109, 062601 (2016).

[6] Y. Trenikhina, A. Romanenko, J. Kwon, J.-M. Zuo, and J. F. Zasadzinski, Nanostructural features degrading the performance of superconducting radio frequency niobium cavities revealed by transmission electron microscopy and electron energy loss spectroscopy, J. Appl. Phys. 117, 154507 (2015).

[7] F. Barkov, A. Romanenko, and A. Grassellino, Direct observation of hydrides formation in cavity-grade niobium, Phys. Rev. Accel. Beams 15, 122001 (2012).

[8] W. Singer, A. Brinkmann, R. Brinkmann, J. Iversen, A. Matheisen, W.-D. Moeller, A. Navitski, D. Reschke, J. Schaffran, A. Sulimov, N. Walker, H. Weise, P. Michelato, L. Monaco, C. Pagani, and M. Wiencek, Production of superconducting 1.3-GHz cavities for the European X-ray Free Electron Laser, Phys. Rev. Accel. Beams 19, 092001 (2016).

[9] J. Knobloch, The "Q disease" in superconducting niobium RF cavities, AIP Conf. Proc. 671, 133 (2003).

[10] A. Dangwal Pandey, G. Dalla Lana Semione, A. Prudnikava, T. F. Keller, H. Noei, V. Vonk, Y. Tamashevich, E. Elsen, B. Foster, and A. Stierle, Surface characterization of nitrogendoped $\mathrm{Nb}$ (100) large-grain superconducting RF cavity material, J. Mater. Sci. 53, 10411 (2018).

[11] A. V. Linde, R.-M. Marin-Ayral, D. Granier, F. BoscRouessac, and V. V. Grachev, Synthesis of cubic niobium nitride by reactive diffusion under nitrogen pressure, Mater. Res. Bull. 44, 1025 (2009).

[12] A. H. Farha, O. M. Ozkendir, H. E. Elsayed-Ali, G. Myneni, and Y. Ufuktepe, The effect of heat treatment on structural and electronic properties of niobium nitride prepared by a thermal diffusion method, Surf. Coat. Technol. 309, 54 (2017).

[13] Y. Ufuktepe, A. H. Farha, S. I. Kimura, T. Hajiri, K. Imura, M. A. Mamun, F. Karadag, A. A. Elmustafa, and H. E. Elsayed-Ali, Superconducting niobium nitride thin films by reactive pulsed laser deposition, Thin Solid Films $\mathbf{5 4 5}$, 601 (2013).

[14] Y. Ufuktepe, A. H. Farha, S. Kimura, T. Hajiri, F. Karadağ, M. A. Al Mamun, A. A. Elmustafa, G. Myneni, and H. E. Elsayed-Ali, Structural, electronic, and mechanical properties of niobium nitride prepared by thermal diffusion in nitrogen, Mater. Chem. Phys. 141, 393 (2013).

[15] B. An, M. Xu, S. Fukuyama, and K. Yokogawa, Nitrogeninduced structures of a $\mathrm{Nb}(100)$ surface investigated by LEED, Auger electron spectroscopy, and STM, Phys. Rev. B 73, 205401 (2006).

[16] P. Dhakal, S. Chetri, S. Balachandran, P. J. Lee, and G. Ciovati, Effect of low temperature baking in nitrogen on the performance of a niobium superconducting radio frequency cavity, Phys. Rev. Accel. Beams 21, 032001 (2018).

[17] E. Fromm and E. Gebhardt, Gase Und Kohlenstoff in Metallen (Springer-Verlag, Berlin, 1976).

[18] M. Lohmeier and E. Vlieg, Angle calculations for a sixcircle surface X-ray diffractometer, J. Appl. Crystallogr. 26, 706 (1993).
[19] E. Vlieg, Integrated intensities using a six-circle surface X-ray diffractometer, J. Appl. Crystallogr. 30, 532 (1997).

[20] A. Stierle, T. F. Keller, H. Noei, V. Vonk, and R. Roehlsberger, DESY NanoLab, J. Large-Scale Res. Facil. 2, A76 (2016).

[21] U. Hejral, P. Müller, M. Shipilin, J. Gustafson, D. Franz, R. Shayduk, U. Rütt, C. Zhang, L. R. Merte, E. Lundgren, V. Vonk, and A. Stierle, High-energy x-ray diffraction from surfaces and nanoparticles, Phys. Rev. B 96, 195433 (2017).

[22] H. Reichert and V. Honkimäki, in Synchrotron Light Sources Free. Lasers (Springer, Cham, 2016), pp. 1557-1577.

[23] H. Dosch and J. Peisl, Unusual diffuse scattering intensities from nitrogen in niobium, Phys. Rev. B 32, 623 (1985).

[24] H. Dosch, Critical Phenomena at Surfaces and Interfaces: Evanescent X-Ray and Neutron Scattering (SpringerVerlag, Berlin, 1992).

[25] H. Dosch, Evanescent absorption in kinematic surface Bragg diffraction, Phys. Rev. B 35, 2137 (1987).

[26] H. Dosch, B. W. Batterman, and D. C. Wack, DepthControlled Grazing-Incidence Diffraction of Synchrotron X Radiation, Phys. Rev. Lett. 56, 1144 (1986).

[27] P. Dhakal, G. Ciovati, P. Kneisel, and G. R. Myneni, Enhancement in quality factor of SRF niobium cavities by material diffusion, IEEE Trans. Appl. Supercond. 25, 1 (2015).

[28] M. Delheusy, A. Stierle, N. Kasper, R. P. Kurta, A. Vlad, H. Dosch, C. Antoine, A. Resta, E. Lundgren, and J. Andersen, X-ray investigation of subsurface interstitial oxygen at Nb/oxide interfaces, Appl. Phys. Lett. 92, 101911 (2008).

[29] J. M. Dickey, H. H. Farrell, O. F. Kammerer, and M. Strongin, Surface studies on niobium and some implications for superconductivity, Phys. Lett. A 32, 483 (1970).

[30] A. B. Odobesko, S. Haldar, S. Wilfert, J. Hagen, J. Jung, N. Schmidt, P. Sessi, M. Vogt, S. Heinze, and M. Bode, Preparation and electronic properties of clean superconducting Nb(110) surfaces, Phys. Rev. B 99, 115437 (2019).

[31] Q. Ma, P. Ryan, J. W. Freeland, and R. A. Rosenberg, Thermal effect on the oxides on $\mathrm{Nb}(100)$ studied by synchrotron-radiation x-ray photoelectron spectroscopy, J. Appl. Phys. 96, 7675 (2004).

[32] C. Varmazis, A. Joshi, T. Luhman, and M. Strongin, Effect of high-temperature heat treatment on penetration depth of superconducting niobium, Appl. Phys. Lett. 24, 394 (1974).

[33] O. Hellwig, H. W. Becker, and H. Zabel, Ordered oxygen phases in epitaxial $\mathrm{Nb}(110)$ layers, Phys. Rev. B 64, 233404 (2001).

[34] See Supplemental Material at http://link.aps.org/ supplemental/10.1103/PhysRevAccelBeams.22.103102 for SEM images and XPS measurements of C 1s core level.

[35] C. Antoine, Materials and Surface Aspects in the Development of SRF Niobium Cavities, EuCARD Editorial Series on Accelerator Science and Technology (EuCARD, 2012).

[36] C. Herzig and Y. Mishin, in Diffusion in Condensed Matter (Springer-Verlag, Berlin, 2005), pp. 337-366.

[37] M. T. Marques, A. M. Ferraria, J. B. Correia, A. M. B. do Rego, and R. Vilar, XRD, XPS and SEM characterisation 
of $\mathrm{Cu}-\mathrm{NbC}$ nanocomposite produced by mechanical alloying, Mater. Chem. Phys. 109, 174 (2008).

[38] A. Daccà, G. Gemme, L. Mattera, and R. Parodi, XPS analysis of the surface composition of niobium for superconducting RF cavities, Appl. Surf. Sci. 126, 219 (1998).

[39] H. Dosch, A. v. Schwerin, and J. Peisl, Point-defect-induced nucleation of the $\omega$ phase, Phys. Rev. B 34, 1654 (1986).

[40] M. S. Blanter and A. G. Khachaturyan, Stress-induced interaction of pairs of point defects in bcc solutions, Metall. Trans. A 9, 753 (1978).

[41] R. P. Kurta, V. N. Bugaev, A. Stierle, and H. Dosch, Incommensurate strain-induced ordering of interstitial oxygen in Nb, J. Phys. Condens. Matter 20, 275206 (2008).

[42] M. A. Krivoglaz, V. G. Baryakhtar, M. A. Ivanov, S. C. Moss, and J. Peisl, X-Ray and Neutron Diffraction in Nonideal Crystals (Springer, Berlin, 1996).

[43] Y. Li, B. An, S. Fukuyama, K. Yokogawa, and M. Yoshimura, Surface oxidation of a $\mathrm{Nb}(100)$ single crystal by scanning tunneling microscopy, Mater. Charact. 48, 163 (2002).

[44] A. Darlinski and J. Halbritter, Angle-resolved XPS studies of oxides at $\mathrm{NbN}, \mathrm{NbC}$, and $\mathrm{Nb}$ surfaces, Surf. Interface Anal. 10, 223 (1987). 